Fibromyalgia is often connected with disability pension : a very long-term follow-up study in Finland

Isomeri, $\mathrm{R}$.

2021

Isomeri , R , Mikkelsson , M , Partinen , M , Kautiainen , H \& Kauppi , M J 2021 , '

Fibromyalgia is often connected with disability pension : a very long-term follow-up study in

Finland ', Scandinavian Journal of Rheumatology , vol. 50 , no. 2 , pp. 167-168 . https://doi.org/10.1080/03009742.2

http://hdl.handle.net/10138/339067

https://doi.org/10.1080/03009742.2020.1771765

acceptedVersion

Downloaded from Helda, University of Helsinki institutional repository.

This is an electronic reprint of the original article.

This reprint may differ from the original in pagination and typographic detail.

Please cite the original version. 


\title{
LETTER
}

\section{Fibromyalgia is often connected with disability pension: a very long-term follow-up study in Finland}

\author{
R Isomeri', M Mikkelsson ${ }^{1,2}$, M Partinen $^{3,4}$, H Kautiainen ${ }^{5,6}$, MJ Kauppi $^{2,7}$ \\ ${ }^{1}$ Department of Physical and Rehabilitation Medicine, Päijät-Häme Central Hospital, Lahti, Finland \\ ${ }^{2}$ Faculty of Medicine, Helsinki University, Helsinki, Finland \\ ${ }^{3}$ Helsinki Sleep Clinic, Vitalmed Research Center, Helsinki, Finland \\ ${ }^{4}$ Department of Clinical Neurosciences, University of Helsinki, Helsinki, Finland \\ ${ }^{5}$ Primary Health Care Unit, Kuopio University Hospital, Finland \\ ${ }^{6}$ Folkhälsan Research Center, Helsinki, Finland \\ ${ }^{7}$ Department of Rheumatology, Päijät-Häme Central Hospital, Lahti, Finland
}

Fibromyalgia (FM) is characterized by persistent and widespread pain, and is often associated with fatigue, sleep disturbances, and other symptoms. FM is common among people of working age and causes significant disability, loss of productivity, use of health services, and increased costs in healthcare $(1,2)$.

FM has been reported to cause significant direct and indirect costs in many countries, $>7000$ EUR annually in Europe and $>10000$ USD in the USA $(1,3,4)$. FM may also lead to patients claiming work disability pension (WDP). The percentage of FM patients on WDP because of FM in different countries varies from $23 \%$ to $35 \%$ (5-7). In a study of 2321 patients in the USA, $35 \%$ received US Social Security Disease Income and 25\% were estimated to be work disabled after 9 years of follow-up (8). Differences in social security laws and practices between Western countries may explain some of the variation.

We have followed 28 patients with FM from a tertiary care hospital for 26 years (9). During the baseline visit, the patients underwent rehabilitation and were individually instructed to exercise and use treatments to maintain their ability to work. The aim of this report was to analyse the rates of WDP in this population.

In 1986, at the Rheumatism Foundation Hospital, Finland, we collected data from 56 patients with widespread pain. They completed a baseline questionnaire with 25 questions and were clinically examined. Of these patients, 42 fulfilled the diagnosis of FM. The follow-up was conducted 26 years later as a detailed postal questionnaire, in which patients were also asked in detail about their work capability.

In total, $28 \mathrm{FM}$ patients participated in the follow-up (26 women and two men; mean age 70 years). Three patients $(11 \%)$ reported having been healed of FM and $23 \%$ had experienced one or several symptom-free periods lasting at least 1 year. At the end of the 26-year follow-up, 13 patients (46\%) were on permanent WDP.
Six patients in this group totally agreed, and three patients somewhat agreed with the claim that 'Fibromyalgia has had the most significant impact on the fact that I have lost my ability to work'. Thus, in total, nine of the patients responded that FM had had the most significant impact on their ability to work. The Kaplan-Meier estimate of FM-related incidence of continuous WDP was $39 \%$ (95\% confidence interval 21-63\%) Figure 1.

Four of the 13 patients on WDP also had other severe diseases (breast cancer, cardiac arrest, cerebral stroke, and spondyloarthritis) during the follow-up before receiving WDP, which may have had an effect

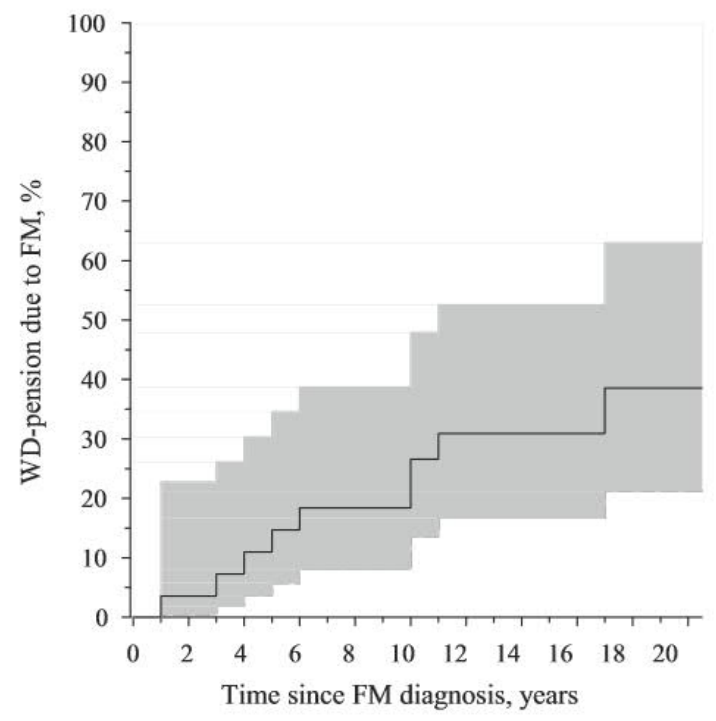

Figure 1. Kaplan-Meier estimates of fibromyalgia (FM)-related incidence of continuous work disability (WD) pension during a 26 year follow-up. The grey area represents bootstrap-type $95 \%$ confidence intervals. 
on their WDP. Most of the disabled patients were manual workers or had worked in service industries. Those who received WDP owing to FM were younger than those who had retired because of other diseases (51 vs 57 years, respectively). If the patient answered in the baseline questionnaire in 1986 that they found the work too heavy, this predicted ( $\mathrm{p}=0.023$, permutation-type log-rank test) an earlier start for the WDP. Seven of the nine patients in the group receiving WDP owing to FM had this opinion. The number of tender points at baseline did not predict the WDP.

The 26 year follow-up time probably reveals the total percentage of FM patients who receive WDP because of FM. The most important result in our study was that the Kaplan-Meier estimate of FM-related incidence of continuous WDP was $39 \%$. This is in line with findings from other Western countries (5-8). We believe that our study provides reliable information on the impact of FM on patients' WDP.

Physically demanding jobs and work tasks are reported to carry higher risks of work disability (6). In our group, seven out of nine patients in receipt of WDP owing to FM had worked in such jobs. Overly strenuous work also predicted WDP being taken up earlier in this study.

When interpreting the results, this was a small study population $(n=28)$ and our patients represented tertiary care patients with severe FM.

Severe FM led to work disability in almost half of the patients during the 26 year follow-up. The need for early retirement may be especially apparent in physically strenuous jobs. Studies evaluating the effects of treatment on work disability in FM are scarce (2). In one study, early diagnosis and intervention was recommended to prevent work disability (7). We emphasize the need for vocational rehabilitation interventions, especially in younger patients. This could diminish the burden on and costs of the syndrome to the patient, employer, insurance company, and community. More studies are needed in this area.

\section{Acknowledgements}

This study was supported by grants from the Finnish Rheumatism Association and the Finnish Society for Rheumatology.

\section{Disclosure statement}

No potential conflict of interest was reported by the authors.

\section{References}

1. Winkelmann A, Perrot S, Schaefer C, Ryan K, Chandran A, Sadosky A, et al. Impact of fibromyalgia severity on health economic costs: results from a European cross-sectional study. Appl Health Econ Health Policy 2011;9:125-36.

2. Palstam A, Mannerkorpi K. Work ability in fibromyalgia: an update in the 21st century. Curr Rheumatol Rev 2017;13:180-7.

3. Rivera J, Rejas J, Esteve-Vives J, Vallejo MA, Rivera J, Silvela F. Resource utilisation and health care cost in patients diagnosed with fibromyalgia in Spain. Clin Exp Rheumatol 2009;27:39-45.

4. Silverman S, Dukes EM, Johnston SS, Brandenburg NA, Sadosky A, Huse DM. The economic burden of fibromyalgia: comparative analysis with rheumatoid arthritis. Curr Med Res Opin 2009;25:829-40.

5. Collado A, Gomez E, Coscolla R, Sunyol R, Sole E, Rivera J, et al. Work, family and social environment in patients with fibromyalgia in Spain: an epidemiological study: EPIFFAC study. BMC Health Serv Res 2014;14:513.

6. Fitzcharles M-A, Ste-Marie PA, Rampakakis E, Sampalis JS, Shir Y. Disability in fibromyalgia associates with symptom severity and occupation characteristics. J Rheumatol 2016;43:931-6.

7. Guymer EK, Littlejohn GO, Brand CK, Kwiatek RA. Fibromyalgia onset has a high impact on work ability in Australians. Intern Med J 2016;46:1069-74.

8. Wolfe F, Walitt BT, Katz RS, Häuser W. Social security work disability and itspredictors in patients with fibromyalgia. Arthritis Care Res (Hoboken) 2014;66:1354-63.

9. Isomeri R, Mikkelsson M, Partinen M, Kauppi MJ. Severity of symptoms persist for decades in fibromyalgia - a 26 year followup study. Clin Rheumatol 2018;37:1383-8.

Markku J Kauppi, Department of Rheumatology, Päijät-Häme Central Hospital, 15850 Lahti, Finland.

E-mail: markku.kauppi@phsotey.fi

Accepted 17 May 2020 